\title{
Memoria y lugar \\ El recuerdo y olvido como forma de conservación de lo inmaterial
}

\section{Octavio Montestruque Bisso}

Universidad de Lima, Perú

Recibido: 4 de agosto de 2015 / Aprobado: 9 de octubre de 2015

La arquitectura pone en valor las edificaciones históricas y genera monumentos alrededor de hechos que se considera deben ser recordados. ¿Qué sucede cuando lo que se busca conservar no es material?, ¿existe un criterio alrededor de la conservación de la memoria desde la arquitectura? El siguiente artículo explora las variables del espacio, el lugar, la memoria, el olvido y la historia como herramientas de las que se debe nutrir la arquitectura contemporánea, para lo que se plantean tres categorías que se pueden identificar en la ciudad de Lima: los espacios de la historia, los espacios para olvidar y los espacios para recordar.

conservación, lugar, memoria, recuerdo, olvido, inmaterial

\section{Memory and Place. Remembrance and Oblivion as a Form of Saving the Immaterial}

Architecture adds value to historic buildings creating monuments about facts considered worthy to be remembered. What happens when something sought to be preserved is not material? Is there a criterion from an architectural perspective about memory conservation? The following article explores the variables of space, place, memory, oblivion and history as tools that shall nourish contemporary architecture, thus three categories maybe identified in the city of Lima: spaces of history, spaces to forget and spaces to remember.

conservation, place, memory, remembrance, oblivion, immaterial 


\section{LUGAR, ESPACIO, MEMORIA Y OLVIDO}

\section{Del lugar al espacio}

La diferencia entre el concepto de espacio y el concepto de lugar radica en la carga cultural intrínseca sobre la cual se posicionan nuestras intervenciones como arquitectos. Según definiciones del antropólogo Marc Auge, el lugar se genera a partir de la apreciación de lo cultural por encima de todas las cosas, siendo entonces el lugar algo que le pertenece a cada individuo y tiene mayor relación con lo inmaterial que con lo material (Auge, 1996).

El lugar es un conjunto de relaciones contextuales y culturales que se dan en un individuo y que se van construyendo a lo largo de toda su vida, influenciado por las experiencias vividas y sobre todo por los contextos en los cuales se ha desarrollado su crecimiento cultural. El lugar es algo que le pertenece al individuo como persona única, pero que puede además verse alimentado desde la perspectiva colectiva, entendiendo que un grupo de individuos con orígenes culturales más o menos similares y que comparten y conviven en un mismo espacio territorial pueden compartir también ciertos patrones de cultura y socialización que les permitirían llegar a un lugar común.

Entendemos así que el concepto de lugar está más relacionado con el campo filosófico, antropológico y metafísico del hombre. Cuando Christian Norberg-Schulz aborda el tema del lugar en la arquitectura, vemos que la fundamentación del genius loci o espíritu del lugar guarda una dualidad entre el territorio como espacio físico y lo divino como espacio intangible. En la antigua Grecia los espacios territoriales eran custodiados por dioses específicos (Reis-Alves, 2009), es decir, cada pedazo de territorio guardaba una mística particular que empezaba a teñir todas las dinámicas culturales y sociales que se desarrollaban.

Sin embargo, este desarrollo sobre el lugar ha cambiado en el tiempo y es en la arquitectura moderna en donde se establece un desprendimiento del sentido místico del territorio para pasar a un sentido pragmático del objeto edificado. Como comenta NorbergSchulz, "el propósito de la arquitectura moderna es la creación de un nuevo lugar donde la vida moderna pueda tener lugar" (Norberg-Schulz, 2005). La industrialización que tomó la vida del siglo XIX constituyó un cambio radical en la concepción del territorio y lo modificó, poniendo en discusión la condición fundamental de la arquitectura como creadora del lugar. De eso se desprende la idea de la arquitectura moderna como algo que va a condicionar la vida del hombre, donde la arquitectura no es únicamente cobijo sino que además debe dar un sentido de pertenencia y significancia (Norberg-Schulz, 2005). En este caso era determinado por el arquitecto, las posibilidades constructivas y tecnológicas, dejando de lado el verdadero espíritu del lugar y reemplazándolo más bien por el espíritu de la época. Si bien en este momento se produce una fractura en la concepción teórica del lugar, se sigue manteniendo éste dentro del plano etéreo de lo espiritual, a pesar de haber pasado de algo divino a algo pragmático.

$\mathrm{La}$ arquitectura moderna, entonces, cambia la concepción del lugar a partir del pragmatismo de la técnica y lo trata de esconder con un velo místico que se desprende de la industrialización del mundo en ese momento. José Ignacio López Soria nos habla de la distinción 
entre espacio y lugar haciendo verdadera referencia al concepto de "ciudadano" en contraposición al de "lugareño" (López Soria, 2011). Aquí, la distinción fundamental radica en la construcción de una artificialidad que va referida al espacio, frente a la naturalidad o ruralidad del territorio sin edificar, que se refiere al lugar. La perspectiva de López Soria recurre al genius loci ${ }^{1}$ original que se inicia en la antigua Roma, y más bien separa y desprende la construcción del espacio de la espiritualidad del lugar.

El espacio es algo que tiene que ver con la intervención y modificación del hombre, mientras que el lugar es algo que se encuentra en su esencia natural y pura, sin ser contaminado por las intervenciones del ser humano, que, dicho sea de paso, corresponde en muchas ocasiones a un entorno cultural diferente al territorio sobre el cual interviene. ¿Puede la arquitectura generar lugar? Si lo artificial constituye un espacio y lo natural un lugar, ¿de qué manera la arquitectura puede conservar la espiritualidad e inmaterialidad de los territorios sobre los cuales interviene? Al mirar en retrospectiva la arquitectura moderna, podemos ver que la búsqueda de un nuevo espíritu de la época que recurriera a una nueva técnica era sincera y encarnaba los principios de moralidad y ética para el ser humano, que se desarrollaba dentro de un mundo en constante cambio.

La racionalidad, en muchas ocasiones, dominó el panorama constructivo, centrando sus

1 En la mitología romana, el genius loci hace referencia al espíritu protector del lugar. Este concepto sería utilizado posteriormente desde la teoría de la arquitectura por Christian Norberg-Schulz, como parte de la rama filosófica de la teoría fenomenológica. fuerzas en la idea de estructura y funcionalidad, dejando de lado la condición humana de la arquitectura para centrarse únicamente en su técnica y así desprenderle el carácter de lugar. El mismo Norberg-Schulz describe la pérdida de la imagen como una característica fundamental de la actual crisis del entorno, haciendo referencia a la imagen misma de la arquitectura como traductora de lo inmaterial. En este caso, la imagen es la encargada de traducir las condiciones del lugar, como se puede ver en la arquitectura desarrollada en la segunda mitad del siglo XX, que se basa en la imagen como portadora de cultura e identidad.

En este caso podríamos hacer referencia a lo que Frampton denomina "regionalismo crítico", y que pone como punto clave los desarrollos arquitectónicos que Le Corbusier plantea desde una monumentalidad vernácula (Frampton, 1998). Después del International Style se busca un retorno a las raíces culturales del espacio y se entiende más que nada como una international technique, en donde lo importante es el espíritu de la época combinado con el espíritu del lugar. Sin embargo, vemos que esta es una historia que se da en donde el desarrollo industrial significó un cambio sustancial en el modo de vida y en los sistemas de producción arquitectónica. En nuestra realidad latinoamericana pareciera que el peso de la espiritualidad del lugar es mayor que el de la época y la técnica, poniendo en jaque el concepto de lugar moderno para una realidad local.

Entonces, ¿cómo podríamos definir una arquitectura del lugar en Latinoamérica? En este caso, es posible que la memoria sea una de las condiciones más importantes, incluso antes que la técnica y la industria.Volver al espíritu del 
lugar sería definitivamente una clave para poder entender una arquitectura que se base en la memoria y que pueda traducir una carga cultural y social pertinente para la reflexión teórica y proyectual de la arquitectura en nuestras ciudades. Así, se propone un regreso al espíritu del lugar por encima de la técnica, pensando que son variables propias de nuestra modernidad.

\section{La historia de la memoria}

La memoria es sin duda una de las mejores herramientas de la historia. Si pensamos que desde hace algunos años estamos sumergidos en una nueva forma de hacer historia y, sobre todo, en una nueva manera de buscar las fuentes que logren constituir la historia (Burke, 2003), entenderemos que estamos también frente a una nueva forma de mirar hacia el pasado. Si partimos entonces de que la historia es una construcción que se da necesariamente en el presente, veremos que este presente está condicionado también por muchas variables, entre ellas, la memoria.

La memoria constituye una de las principales formas de hacer historia en la actualidad, ya que nos habla de una situación del pasado y del presente y nos sumerge en las formas de hacer historia que proponen la nueva historia de Burke $^{2}$ o la larga duración de Braudel ${ }^{3}$. Si pensamos que esta nueva historia constituye una apertura a las variables historiográficas con las cuales podemos trabajar, veremos que la

2 Correspondiente al texto Formas de hacer historia, de 1991, donde Peter Burke es editor y colaborador originalmente, en el que se aborda el concepto de "la nueva historia".

3 Correspondiente al tercer capítulo del libro La historia y las ciencias, de Fernand Braudel, publicado por primera vez en francés en 1958. apertura hacia un mundo de lo cotidiano en donde lo importante son las estructuras más que los hechos, es algo que se presenta frente a nosotros y que se debe entender como una forma de abordar el proceso de investigación.

En la actualidad se considera que la historia está construida por las estructuras del pasado y no solamente por los hechos específicos que pudieran delatar situaciones particulares. Podemos ver que las nuevas formas de hacer historia se remiten hacia temas mucho más personales y particulares, y a partir de eso poder entender una globalidad histórica que nos permita determinar el desarrollo cultural y social del mundo. La manera de abordar la historia a partir de lo cotidiano y no de los hechos específicos, nos lleva definitivamente a una nueva manera de lograr la recopilación de los datos y de las fuentes de investigación.

Así, la historiografia empieza a mostrar interés por las diversas formas de hacer historia y con diversas maneras de recopilar información, como lo hacen Richard Sennet con la microhistoria, Joan W. Scott con la historia de las mujeres, o Ivan Gaskell con la historia visual. Una vez que se genera esta apertura, el campo de lo subjetivo es el que empieza a dominar el panorama, y por lo tanto la manera de aproximarse a las diferentes fuentes de información también va a cambiar. La aparición de las entrevistas, los documentos escritos no oficiales, las imágenes y la nueva importancia que toma la tradición oral, son diversas formas de manifestar un deseo de comprender la historia desde una nueva perspectiva.

A partir de la diversidad de fuentes aparece la memoria como una de las variables más importantes de esta nueva historiografia, ya que es justamente esta memoria la que 
empieza a hablarnos del sentido cotidiano de las cosas. Las nuevas fuentes de investigación de lo cotidiano nos sitúan en la subjetividad y en la particularidad de los eventos, para lo que es necesario contar con vestigios (Burke, 2003) que nos muestren la percepción de las personas sobre la realidad misma. Además, la memoria tiene la ventaja de mostrarnos muchas dimensiones de la realidad, ya sea de la que se está recordando referida al pasado o de la situación actual en la que se recuerda que está referida al presente. Así, la memoria nos puede contar muchas más cosas que los documentos escritos oficiales, y logra enriquecer de forma significativa la construcción histórica.

\section{Del recuerdo al olvido}

Si bien el recordar nos pone frente a una de las variables más importantes de la memoria, el olvido -como diría Elizabeth Jelin (2012)constituye una de las claves más claras para comprender la historia desde un punto de vista contextual. Así como existen comunidades y sociedades que viven del recuerdo y que basan su historia en el rememorar épocas de catástrofe y terrible sufrimiento como una forma de supervivencia (Sztulwark, 2006), también podemos entender el despertar de algunas sociedades a partir del olvido, o mejor dicho, del recuerdo reciente de la historia olvidada.

Jelin menciona que en las sociedades latinoamericanas las épocas de dictadura y de gobiernos autoritarios nos han sumido en una profunda historia negra, en donde los vestigios de la realidad se deben rastrear a partir de lo que omite la historia, buscando además a los autores y sus propias historias, que son quienes finalmente van a transformar un relato en la realidad oficial. Cuando Manuel Gausa define la memoria como "siempre selectiva, con oportunas amnesias tácticas" (Gausa, M. et al., 2000), nos habla de una memoria que se basa en el recuerdo -que además define como selectivo- pero que también contempla la idea de olvido, que en este caso desliza como tentativa la voluntad de olvidar. En este punto, podemos ver que la memoria se da en una dualidad entre lo que recuerdo y lo que dejo de recordar, como una construcción fragmentada pero además contrastada y complementaria.

Por otro lado, José Morales presenta una versión más amplia de la definición de memoria, privilegiando el recuerdo por encima de todo: "son las figuras que nos aparecen fundamentalmente viendo el mundo inconcluso y fragmentario de todo aquello que es la ciudad y sus arquitecturas" (Gausa, M. et al., 2000).Aquí, se hace una clara referencia a la memoria de la arquitectura y la ciudad como una forma de construcción que va más allá de la aplicación de los materiales constructivos y más bien se da en el intersticio de la realidad y la ficción mediante la percepción individual. El mismo autor continúa definiendo la memoria como algo que:

[...] se apoya en el carácter no lineal del tiempo y sus figuras. Se fundamenta sobre el recuerdo, la distorsión y el reenvío. La memoria trabaja con aquello a lo que se liga despidiéndose, se ata a lo que se desvanece, actúa sobre lo que se diluye, así como se data sobre nuevos orígenes. (Gausa, M. et al., 2000)

En este caso vemos que la memoria está directamente relacionada con su opuesto, el olvido, por lo que siempre se ve la idea del recuerdo como el constructor y el olvido como el diluyente de la realidad. Pero, ¿es cierto que el olvido como diluyente de la realidad sea algo 
negativo?, ¿es acaso el olvido algo que va en contra del recuerdo, o más bien se debe explorar para poder entender sus capacidades históricas?

Si bien las definiciones anteriores nos sitúan en una visión positivista sobre el recuerdo, el proceso que va del recuerdo al olvido puede ser central para poder comprender el desarrollo histórico de nuestras sociedades. Si nos situamos en una sociedad joven como la latinoamericana, podremos comprender que el olvido para nuestro caso pueda significar algo más que un simple lapsus o una omisión intencional, sino más bien una ventana para poder comprender el estado cultural y social del pasado. En este sentido, el olvido parece parte primordial para poder comprender el contexto cultural de una sociedad.

Sin embargo, podemos ver que existen épocas en la historia de la arquitectura que basan su producción proyectual a partir del olvido intencional, muchas veces borrando la historia, para poder dar paso a un marco nuevo de construcciones a partir de la tabula rasa y generando su propia idea de memoria e historia. Como ya vimos anteriormente, la arquitectura moderna basa su noción de lugar en la idea de "lugar para la vida moderna", es decir, la construcción de la memoria histórica a partir del presente que se edifica en el momento con una intensa proyección a futuro, pero sin tener mucha consideración del pasado. A pesar de la fuerza y actual vigencia de ciertos dogmas modernos, podemos ver que la arquitectura ha logrado avanzar en su definición de lugar, que es punto clave para poder entender la idea del recuerdo y del olvido. En este contexto, Manuel Gausa nos dice:

[...] la ciudad contemporánea no puede seguir asimilándose a un solo lugar ideal, ni tampoco a un único o posible modelo formal, sino que debe ser contemplada como ese multiespacio mestizo, dinámico y definitivamente inacabado, hecho de convivencias y evoluciones interactivas y enlazadas. (Gausa, M. et al., 2000)

En el mismo texto, Fernando Porras nos dice que el "lugar no tiene que ver con cuestiones de dimensión. Lugar no tiene que ver con asuntos de memoria. Lugar no tiene que ver con aspectos referenciales. Lugar es conexión más allá de lo físico. Lugar es anímico o ideológico" (Gausa, M. et al., 2000).

Bajo estas definiciones, vemos que la idea de la memoria en la arquitectura no solo se desprende de una idea de recuerdo u olvido, sino más bien de una condición ideológica y pluridimensional que nos habla de un cuerpo heterogéneo sobre el cual se debe plantear la nueva manera de abordar la arquitectura. Con esta perspectiva, nosotros podríamos trabajar a partir de una arquitectura que maneja el lugar como un estímulo para la producción de la novedad arquitectónica desde la nueva dinámica social que se maneja en el espacio, asumiendo además que este nuevo espacio se construye en un lugar con memoria, pero sobre todo que la memoria es algo propio de las sociedades y no tanto de los lugares.

Así, los nuevos espacios que se generan en la ciudad deben tener, sin duda alguna, una noción de memoria con proyección social y cultural que una obra arquitectónica puede contemplar, ya que situándonos en el contexto histórico, una obra de arquitectura siempre habla de un presente con proyección a futuro, a pesar de que se apoye o no en algunas variables históricas del pasado. Es decir, la arquitectura, como el olvido, nos pueden hablar de un 
presente sobre el cual se edificará el futuro de una sociedad y de una profesión.

\section{LOS LUGARES DE LA MEMORIA}

\section{Espacios de la historia}

La arquitectura y la ciudad se construyen de algo más que piedras, cemento y ladrillo. La arquitectura tiene mucho que ver con la historia y con la memoria de un lugar determinado, y por lo tanto de la sociedad que la habita y finalmente es responsable de su rumbo. Así, la arquitectura, como bien cultural de una sociedad, debe entender que está trabajando sobre espacios que cargan con su propia memoria y con su propia historia, por lo que debe ser cuidadosa con lo que plantea y propone.

Los espacios de la historia son aquellos que han tenido una carga histórica resguardando ciertos acontecimientos específicos que hayan tenido una relevancia importante para la sociedad a la cual han afectado. Sobre estos espacios las sociedades construyen normalmente una suerte de "altares de la memoria", infraestructuras arquitectónicas o artísticas que servirán para marcar espacialmente el hito histórico que alberga este lugar.

Si bien la historia como la presentan Burke y Braudel dista mucho de la concepción clásica de ser una sucesión de hechos específicos que originan cambios dramáticos en el curso de las sociedades y ya ha caducado (Braudel, 2006), podemos ver que la nueva manera de pensar la historia se da por el conocimiento de las estructuras que vinculan todos los campos sociales, por lo que lo cotidiano empieza a tener una relevancia bastante importante.
Desde la arquitectura se puede entender este mismo proceso cuando se determina una serie de variables históricas para los edificios construidos (Waisman, 1993), que van referidos sobre todo al tiempo en el que se construye el objeto y la influencia que este tiene.

Esta concepción de la historia que se entiende como un cuerpo fraccionado $\mathrm{y}$ compartimentado en categorías específicas, es una herencia de la tradición moderna que entiende el nacimiento de la historia y del hombre racional a partir del siglo XIX y se intensifica durante el siglo XX. Esta aproximación nos sumerge en una parcialización clara de los conceptos históricos y muchas veces no nos permite asomar para encontrar los nuevos horizontes que plantea la relación entre las estructuras sociales y la arquitectura que se genera en éstas. Así, las ciudades contemporáneas crecen y empiezan a dejar en su camino ciertos rastros de la civilización, y es hoy en día cuando hemos aprendido a valorar el pasado como parte constituyente de nuestra cultura. Si bien la modernidad trató de borrar estos espacios de la historia, podemos ver que la herencia que nos deja este movimiento es la de un panorama aún más frágil y desolado que el que se encontraron estos personajes al momento de proyectar la nueva arquitectura de la nueva época (de Solà-Morales, 2002).

Sin embargo, en la actualidad no podríamos imaginarnos las ciudades y la arquitectura sin sus espacios de la memoria, es decir, sin sus monumentos representativos que son el vestigio de una historia anterior. Pensar entonces en ciudades como Roma, Atenas o Madrid, que se hayan despojado de su arquitectura histórica para darle paso a una 
arquitectura moderna, carece de sentido en la actualidad. Así, la arquitectura sirve como un testimonio de la cultura de un lugar determinado, comprendiendo que este debe ser preservado y entendido como una fuente de conocimiento de primera mano, ya que nos habla no solamente de estilos y sistemas constructivos, sino además de lo que significó la historia y lo importante para una sociedad en un momento y lugar determinados.

Posiblemente el mayor reto que presenta la arquitectura en estos momentos sea el de pensar de qué manera se pueden conservar los espacios de la historia, entendiendo que si bien tienen un valor por haber sido el escenario de un hecho representativo, también deben albergar ciertas dinámicas actuales para garantizar su supervivencia. De lo contrario los espacios de la historia estarían quedando como ruinas olvidadas que no hablarían de un pasado, sino más bien de una desidia del presente que se niega a conservar su cultura y sociedad tradicional.

Los espacios de la historia son importantes, entonces, no solo como vestigio de lo que sucedió, sino también como presente e historia viva que se sigue construyendo en la medida en la que se siga pensando en ellos como piezas claves y fundamentales de la arquitectura y la ciudad contemporáneas. Los espacios de la historia deben ser los espacios más vivos de las ciudades, ya que albergan una antigüedad y una carga.

\section{Espacios para olvidar}

Si bien las ciudades han ido transformando los lugares, convirtiéndolos en espacios, y nos han llevado de la condición de "lugareños" a la condición de "ciudadanos" (López Soria,
2011), podemos ver que cierta arquitectura ha logrado sobrevivir más que otra, muchas veces no por un sincero valor histórico, sino más bien por una clara vocación de olvido por parte del presente en el que se situaron. Es aquí donde la modernidad cobra un papel importante como transformadora del vestigio histórico que compone la ciudad, para dar paso a lo que se entendía como el nuevo espíritu de la época.

Si bien es cierto que la modernidad trajo consigo muchos beneficios, sobre todo en el campo técnico y tecnológico, así como en el político y social, podemos ver que en la arquitectura se empezó a arraigar una serie de dogmas que terminaron siendo estrictamente totalitarios, en donde no se podía concebir ningún tipo de historia más que la presente, borrando el pasado y buscando conquistar el futuro. No fue sino hasta mediados del siglo XX que la retrospectiva moderna empezó a valorar el pasado y a reconocer los crímenes de exterminación que se habían cometido. Así, se empiezan a presentar ciertas tendencias retrospectivas en la modernidad madura (Frampton, 1998), que a pesar de buscar sus fuentes de inspiración en el pasado, siempre terminaban siendo autorreferidas.

En este contexto, lo que la arquitectura moderna hizo con las ciudades fue transformarlas, y en muchos casos empezó a imponer sus nuevas estructuras sobre las existentes, de tal forma que la memoria y la historia se renovaran desde un "punto cero", generando así un inicio del pensamiento y una antigua era de oscuridad. Para esto, los edificios que guardaban cierto valor histórico en las ciudades fueron desapareciendo y dando paso a una nueva 
manera de entender el lugar y el espacio arquitectónico, generando así una suerte de dictadura donde todos debían estar alineados bajo el mismo pensamiento y cualquier situación de revolución podría ser calificada de acto muy grave por parte del gremio.

En nuestro país la situación no fue diferente, ya que la arquitectura moderna vino cargada de un aire de revolución, pero huérfana en el sentido técnico y tecnológico, dejando algunos retazos de pensamiento y obras aisladas de gran valor espacial. Si bien esta época en nuestro país significó un despertar de la conciencia arquitectónica, llegando a tener incluso espacios de opinión y referencia en el ámbito político y social, esta fiebre juvenil nos deja como saldo una ciudad aún más fragmentada y desmemoriada respecto a su pasado, tratando de imponer sistemas importados a un contexto que distaba mucho de la tradición moderna occidental.

Resulta curioso que sea esta arquitectura moderna la que se ve amenazada por el actual crecimiento inmobiliario que va arrasando con nuestra ciudad sin ninguna reflexión o conciencia histórica, más allá de la ganancia máxima y explotación del mercado. Evidentemente la sociedad actual, acostumbrada a los cambios constantes, ve como algo positivo la desaparición de estos edificios poco rentables para el mercado inmobiliario. Posiblemente esta sea una de las herencias más peligrosas que dejó el espíritu moderno en las ciudades, una sociedad acostumbrada al olvido rápido y la poca valoración de la memoria arquitectónica, para dar paso a una renovada imagen urbana que se aleja de los estándares básicos de habitabilidad.

\section{Espacios para recordar}

La tercera categoría que se desprende de estos espacios de la memoria, es la que denominaremos espacios para recordar. $\mathrm{La}$ característica principal de estos espacios es que recogen la tradición moderna en cuanto a la generación de un nuevo lugar referido a sí mismo y que guardan muy poca relación con el contexto geográfico o histórico en el cual se sitúan. Estos espacios para recordar buscan combinar la idea de construcción fragmentaria de la ciudad a partir de ciertos principios caritativos que reconocen que la historia es algo importante, no importa dónde se encuentre, siempre y cuando se recuerde.

Los espacios para recordar, que históricamente nacen después de la modernidad, son estructuras arquitectónicas generadas para recordar hechos o situaciones de relevancia social y cultural, pero que no guardan ninguna relación con el contexto físico en el que se sitúan estos hechos, más bien basan sus principios en discursos que buscan rememorar y extrapolar situaciones ajenas al lugar en el cual se edifican. Posiblemente el prototipo más importante de este tipo de arquitectura sean los museos y los memoriales, que se establecen como una artificialidad geográfica para lograr dialogar a través del espacio interior, de las sensaciones espaciales y de los guiones museográficos que se plantean en su recorrido.

Lo que buscan estos nuevos edificios es resguardar una memoria ya desaparecida y muchas veces trastocada, casi como si se escribiera un nuevo libro de historia. La idea del edificio como protagonista de los relatos históricos desaparece, y más bien se ve incorporado en una serie de dinámicas que buscan mostrar posturas y direcciones 
claras sobre la interpretación histórica. Es por eso que la analogía del edificio para recordar tiene mucho que ver con la idea del libro de historia, ya que se parte de una postura propia -ya sea del proyectista, del benefactor o del promotor- que plantea la realidad desde un punto de vista establecido.

Los museos, además, significan una forma de mostrar y resguardar la historia, a pesar de que no concuerden en muchas ocasiones los propósitos originales de su concepción con lo que realmente significa para la sociedad el tener un espacio para recordar. Desde esta perspectiva podemos ver que los museos se pueden plantear desde el contenido de sus exposiciones (Museo de Arte Moderno, Museo de Bellas Artes, Museo de Antropología), desde sus principales personajes creativos (Fundación Miralles, Fundación Joan Miró, Fundación Le Corbusier), o poniendo en alto el nombre de los principales benefactores del museo (The Frick Collection, Museo Reina Sofia, Museo Guggenheim).

De esta manera, los espacios para recordar nos presentan en muchas oportunidades una gama de variables de la memoria sobre las cuales se establece qué debe ser recordado y qué no. Esta vocación forzada del recuerdo nos impone una conciencia predestinada que va más allá de los acontecimientos históricos y de las variables que se manejan en la actualidad a partir de la nueva historia, retrocediendo a hechos o personajes específicos que en muchos casos no tienen nada que ver con la historia que se pretende resaltar.

Dentro de esta misma categoría aparecen los espacios denominados memoriales, posiblemente los más enfocados en las sensaciones y en la reconstrucción de una estructura social de memoria que va más allá del acontecimiento específico, pero que además tienen una translocación bastante fuerte, ya que se ubican en un contexto diferente al de los espacios de la historia, creando así su propio contexto y por lo tanto su propio valor e imaginario como nuevo espacio para recordar. Este tipo de arquitectura se desprende de situaciones de conflicto extremo o de fuerte trauma para la sociedad, a partir de las pérdidas por guerras, desastres naturales o conflictos internos.

De esta forma vemos que la arquitectura busca diferentes maneras de hacerse presente en la historia y sobre todo en la memoria de las sociedades contemporáneas, actuando directamente en la cultura y en las estructuras que nos reclama la nueva historia. Es por eso que la importancia del análisis de los edificios y la arquitectura no debe radicar únicamente en sus ideas compositivas, sino en sus repercusiones sociales y culturales, ya que los edificios representan uno de los vestigios más importantes de la época, hablándonos de un presente y de un pasado y ayudando a proyectar el futuro de la ciudad.

\section{TRES CRÍTICAS SOBRE LA MEMORIA}

\section{Del lugar al espacio}

En Lima existían nueve reductos que conformaban una línea de defensa de la ciudad ante la invasión chilena en 1881. De todos estos espacios de defensa, en la actualidad solo sobreviven los de Miraflores (Reducto 2) y de Surquillo (Reducto 5), a pesar de que esta línea de defensa atravesaba los actuales distritos de Miraflores, Surquillo, Surco, San Borja y La Molina. Como se puede ver en el cuadro de 
Juan Lepiani sobre el Reducto 3, este espacio tenía unas características un tanto anodinas -un paisaje árido y sin referencias geográficas claras, que podría ser ubicado en cualquier parte de la costa peruana-, en donde la historia se escribe a partir del hecho y no tanto del espacio en el cual se desarrolla.

Es por eso que los reductos de Lima constituyen un valor para la historia desde el punto de vista territorial, ya que es en esos espacios donde se desarrollaron eventos importantes de la Guerra del Pacífico. Si bien en su momento lo importante no era el espacio sino el hecho histórico, en la actualidad podemos exaltar ese espacio conservándolo como un vacío urbano. La Batalla de Miraflores fue en 1881, pero el espacio conocido en la actualidad como Parque Reducto no se declara como espacio histórico y monumento nacional sino hasta 1944. Es curioso que la denominación de Reducto 2 sea la de "monumento nacional", ya que esta idea de monumento está normalmente dirigida a los objetos y no a los espacios, por lo que el lugar empieza a tomar una categoría de pieza aislada más que de espacio habitable.

El Parque Reducto se mantiene como un espacio bien conservado en la ciudad, pero posiblemente sus cualidades de espacio de la historia se vean mermadas debido a ciertas acciones sobre el lugar en el que se instala. El carácter histórico que se busca en este espacio, mediante la conservación del parapeto de piedra, las piezas militares encontradas en el lugar y la construcción de un museo, no es suficiente para dialogar con la sociedad.

A pesar de los constantes actos conmemorativos, en donde la presencia castrense es lo más resaltante, podemos ver que el espacio del Reducto 2 constituye más que nada un vacío poco utilizado antes que un real espacio para poder entender la historia que se desarrolló en este lugar. Si pensamos que este espacio no carece de presupuesto, ubicación o relevancia histórica, no se puede entender rápidamente la escasa afluencia del público, y sobre todo la poca comunicación que se tiene entre la arquitectura y la historia. Es aquí en donde la importancia de la arquitectura como medio para conservar la historia aparece, y mientras no exista un diálogo constante entre arquitectura y sociedad, es dificil pensar que se pueda crear un espacio de la historia que sobreviva mucho tiempo y que además genere relaciones con la ciudad.

Mientras que este espacio busque un aislamiento de la ciudad -posiblemente para poder garantizar su preservación y mantenimientoy no existan actividades realmente públicas o licencias para la libertad de acción, será difícil que sea un lugar inclusivo e integrador con el vecindario y con la ciudad. El hecho de recordar un evento como la Batalla de Miraflores es definitivamente algo importante para la preservación de la historia, el problema es que si seguimos pensando en una manera de transmitir la historia que no evoluciona junto con la sociedad, será muy complicado pensar que estos espacios logren comunicar lo que se quiere recordar. Como contraparte, un espacio de similares características sería la Pampa de la Quinua en Ayacucho. Vemos que es bastante más activo y vivo, pues permite una serie de actividades que van más allá de lo que permite el museo o monumento y que logran reunir a una sociedad alrededor de un lugar que merece la pena ser recordado.

Este espacio de la historia, entonces, no plantea nuevas dinámicas urbanas. Se queda ceñido a una memoria del hecho histórico y no de la 
estructura social que se vio afectada, es decir, la manera de abordar la arquitectura no es generadora de nuevas dinámicas y aportes sociales para la comunidad. La arquitectura, por lo tanto, debe ser una correspondencia de una serie de posturas frente a las cosas, en este caso la historia, por lo que debería proponer más y mejores variables del espacio para que se genere un verdadero punto de reunión alrededor de la historia.

\section{Vacios y ausencias}

La modernidad es un punto clave para poder entender la arquitectura desde la memoria. En muchas ocasiones se ha entendido este influyente movimiento como la salvación a la proliferación de arquitecturas que caían en lo retórico y poco racional, encarnando la nueva verdad -casi de manera mesiánica- sobre la arquitectura y su futuro. Sin embargo, esta arquitectura dio paso a una nueva conciencia del olvido, donde se entendía que la nueva historia, la nueva memoria y el nuevo lugar nacían en ese preciso momento.

En nuestro país la situación no fue muy diferente. Mientras que en Occidente ya se estaba entrando en una etapa madura de la modernidad, en el Perú los ímpetus revolucionarios estaban en plena efervescencia. Los arquitectos modernos fueron muchas veces acaparando el mercado proyectual y diferenciándose de sus colegas que buscaban tendencias más clásicas y conservacionistas, como en el caso de las caricaturas publicadas en El Comercio sobre la obra de Emilio Harth-Terré.

Las posiciones más diplomáticas, como las de Héctor Velarde, también se vieron afectadas por este impulso moderno, y fue posiblemente este arquitecto quien mejor supo llevar la etapa de transición que se dio en el país al llegar la modernidad. Esta etapa se ve caracterizada por una constante lucha por la supervivencia de la historia, enfrentada a una tendencia de renovación y de renacimiento, por lo que es fácil entender la manera en que la ciudad que se empezaba a construir se posicionaba encima de la ciudad existente. Desde el punto de vista urbanístico, la apertura de grandes avenidas y corredores vehiculares mutilan la ciudad y su arquitectura.

Uno de los casos más saltantes puede ser el de la construcción del campus universitario de la Universidad Nacional Mayor de San Marcos, en la década de 1950, en donde el Estadio de San Marcos se ubicó encima de la Huaca San Marcos. En confesiones posteriores del diseñador, el arquitecto Alfredo Dammert, se dice que la ubicación se dio expresamente en ese lugar ya que la estructura espacial de la huaca lograba facilitar la construcción del estadio sin tener que invertir mucho dinero. En este caso, la destrucción de este complejo arqueológico no radicaba en una expresa necesidad de borrar la historia, sino más bien en una inocente desidia con respecto de la conservación de las estructuras prehispánicas en la ciudad. Evidentemente, este olvido de la historia nos habla de una época en donde los conceptos de preservación o de conservación no eran abordados como algo importante, ya que la historia se estaba construyendo en ese mismo momento con los nuevos edificios modernos.

A pesar de esto, podemos ver buenas intervenciones respecto a la memoria de la arquitectura y la modernidad. El caso de la intervención de Alfredo Montagne en el Banco 
Mercantil del centro de Lima, corresponde a una nueva manera de entender la memoria arquitectónica. Lo que hace esta ampliación de 1986 es tomar la esquina vacía de un edificio histórico, para lograr cerrarla y consolidar ese pedazo de ciudad mediante una intervención moderna. En este caso los materiales a utilizar corresponden a una nueva manera de entender la técnica en pro de la recuperación de la memoria arquitectónica, ya que la ampliación pensada en vidrio y metal guarda un lenguaje moderno pero que busca rememorar las líneas guías del diseño Art Nouveau del antiguo edificio.

Las cornisas de la estructura anterior se ven respetadas y más bien realzadas por las nuevas líneas del edificio moderno, y la transparencia del vidrio nos habla de un vacío anterior que se ve cerrado por las nuevas necesidades de la vida moderna. En este caso, las indicaciones de Norberg-Schulz respecto al nuevo lugar de la vida moderna, son interpretadas de forma bastante efectiva para poder resaltar los conceptos compositivos clásicos. Si bien lo que cambia son las posibilidades espaciales gracias a la nueva técnica, la armonía con el conjunto se ve enaltecida por mérito de la nueva intervención.

La desidia que se genera a partir de la modernidad sobre la arquitectura de la ciudad, convierte a la sociedad en un grupo de personas que han sacado a la arquitectura como valor histórico o cultural, por lo que posiblemente no encuentren muchos reparos en su depredación. La arquitectura moderna, por ser reciente, no logra tener la categoría histórica que pueda generar cierto nivel de identificación con la sociedad, siendo más bien las estructuras clásicas las que evocan mayores sentimientos nostálgicos por parte de la población que no está relacionada con la profesión arquitectónica. Así, la costumbre del olvido se enraíza en nosotros y en la sociedad, restándole valor a la profesión arquitectónica y a sus edificios.

\section{Imaginarios y huellas}

El último caso que abordaremos en este artículo será el del Lugar de la Memoria, promovido por una iniciativa de la Comisión de la Verdad y un grupo de intelectuales del medio, que buscaban recordar una época negra para la sociedad peruana. El tema central de este espacio es el de recordar los años de violencia y terrorismo que vivió nuestro país, pero que a pesar de estar esta memoria ubicada geográficamente en la sierra peruana, el nuevo museo se ubica en un espacio de la CostaVerde, frente al mar, en un paisaje muy diverso al que se podría relacionar con estos terribles sucesos. En este caso la iniciativa busca la generación de un espacio para recordar, aunque la ubicación no corresponde a una memoria relacionada con el tema de exposición.

Este concurso público que generó un gran espacio de discusión para la sociedad y la arquitectura, fue ganado por la oficina nacional Barclay \& Crousse, con un proyecto que aborda el tema de la memoria desde muchas dimensiones y que trasciende el tema principal del programa para abordar además una memoria que corresponde al lugar específico en el cual se sitúa. En primer lugar, el emplazamiento del edificio busca la recuperación de una memoria geográfica de los acantilados de la Costa Verde, dialogando directamente con el contexto natural y enlazándolo con la artificialidad construida. 
La posición y estructura responden a temas bastante prácticos, como la mala calidad del suelo, por lo que se busca generar un edificio de características lineales que se apoye en la menor superficie posible. Este volumen monolítico se convierte en un farallón artificial que busca dividir, a manera de frontera edificada, el sector generado naturalmente en la Costa Verde mediante muchos años de erosión, y la construcción artificial de los farallones posteriores, creados a partir del relleno $y$ desmonte de construcción de la ciudad.

Este frente costero se edifica a partir de la memoria geográfica que se da, marcando una pauta y una señal para toda la sociedad que visitará este sector de la ciudad. Además, la posición de este edificio genera no solamente una separación física, sino también un espacio público de grandes dimensiones que logra integrar la parte superior del distrito con la bajada al mar mediante la arquitectura. Lo que se espera es que este vacío urbano se convierta en un nuevo espacio de interacción para la ciudad, que más allá de la poética del lugar, busca generar un nuevo espacio público para Lima.

Por otro lado, la estrategia discursiva del edificio no se remite a una idea de recuerdo como algo doloroso, ya que se entiende que la arquitectura no está para traer memorias trágicas, sino más bien para enaltecer la vida humana (Arkinka, 2010). Esto se corresponde con el documento entregado por la Comisión de la Verdad, en donde se ve que las discusiones sobre la memoria de esta época se dividen entre las personas que no quieren recordar los hechos - mayoritariamente en la sierra peruana- y los que sí buscan recordar -concentrados en la capital-.
Así, el edificio pretende, mediante espacios caracterizados en el discurso arquitectónico como la Explanada de la Reconciliación o la Plaza del Congojo, evocar vivencias y memorias donde las características espaciales puedan ser tomadas de los eventos posteriores a la época de terror nacional. Un espacio de las características de la Plaza del Congojo puede ser relacionado fácilmente con las procesiones de la sierra e incluso con las imágenes difundidas sobre entierros colectivos que se dieron en la sierra del Perú. Estos espacios buscan, a pesar de la trastocada ubicación, la construcción de una nueva memoria colectiva que pueda unificar los sentimientos de un momento que se dio en el país. Se puede entender como algo que difiere en todos los casos, que nos une a partir del miedo, y se convierte en una estructura bastante necesaria para poder comprender lo que somos como sociedad.

Es importante mencionar que el recuerdo y la memoria buscan establecer ciertas nociones de recuerdo con hechos del pasado, y deben reflejar una voluntad de colectividad mediante espacios que busquen justamente la interacción entre los ciudadanos. La idea del imaginario a partir de situaciones de crisis y de terror no debe remarcar estos momentos dolorosos, sino simplemente hacerse presente mediante la reunión de diferentes actores sociales y urbanos para poder establecer nuevas dinámicas colectivas.

Posiblemente sea dificil establecer el grado de impacto que tenga este edificio como espacio de la memoria y del recuerdo, al menos hasta el momento de su inauguración y posterior habitabilidad.Definitivamente, la mejor manera de establecer estas dinámicas de memoria es 
mediante la creación de espacios colectivos que nos lleven a la reunión alrededor de objetivos comunes como sociedad. Por suerte, la controversia generada a partir de la creación de este espacio, ha logrado trascender el ámbito arquitectónico para situarse en el campo social, situación que desde hace mucho tiempo no se lograba con la construcción de un edificio. La poética de la arquitectura no es nada sin la aceptación o transformación de la sociedad en la cual se establece, por lo que no se puede sentenciar el proyecto hasta el momento de su comprobación vivencial.

Esperemos, pues, que este espacio del recuerdo logre encarnar las expectativas de una población que hace muchos años se ve carente de memoria y redundante de olvido, en todas sus dimensiones, y que sea a partir de la arquitectura de donde podamos empezar a construir una nueva conciencia y una nueva sociedad que entienda que la memoria constituye un presente, que debe ser entendido también como un hecho histórico.

\section{CONCLUSIONES}

Las conclusiones que se desprenden de este breve análisis en relación con la arquitectura y la memoria, a partir de sus intervenciones en la ciudad, son diversas y en muchos casos alarmantes. Hemos visto la manera en que los espacios de la historia, que son abundantes en nuestra ciudad, se han visto olvidados por la falta de dinámicas públicas que los incentiven, por lo que es importante centrarnos en generar una memoria viva que se enfoque en lo urbano y en las capacidades cívicas que podamos plantear implementando la idea de la conservación de lo inmaterial como posibilidad de activación del espacio. La historia que nos rodea no es únicamente cuestión del pasado, sino que debe ser entendida como un acontecimiento del presente que logre generar nuevas líneas de reflexión alrededor de la arquitectura y la ciudad.

La búsqueda del International Style nos ha llevado a grandes épocas de amnesia colectiva, iniciadas curiosamente en decisiones políticas y arquitectónicas sin medir las consecuencias futuras que estas plantean. Es aquí donde radica la importancia de comprender la conservación de la historia como un presente y como una construcción constante que se da a partir de la vigencia de las dinámicas urbanas.

A pesar de tener ciertos vestigios de conservación de la memoria y de reivindicación, por parte de la arquitectura, con las dinámicas sociales del país, vemos que estamos entrando en una nueva etapa en donde el olvido o el recuerdo pasan de lado para dar lugar a la desidia que implica la transformación de la ciudad a partir de las inversiones privadas. La arquitectura, desde este punto de vista, debe buscar un protagonismo perdido en las implicancias políticas y sociales del país, solamente así podremos entender que la memoria y la arquitectura no solo guardan puntos en común sino que deben ser entendidas como una unidad que trasciende el campo profesional y que debe tener una proyección de relevancia social para poder construir ciudades para ciudadanos.

La conservación debe ser, entonces, una de las abanderadas de la recuperación histórica a partir de la construcción del presente, ya que ésta, al igual que la historia, se sitúa en un aquí y ahora que debe ser recuperado para no caer en el consuelo del pasado y la tragedia del futuro. 


\section{REFERENCIAS}

Arkinka. (mayo del 2010). Concurso Arquitectónico Lugar de la Memoria. Coloquio. Arkinka, 13-29.

Auge, M. (1996). Los no lugares. Espacios del anonimato. Una antropología de la sobremodernidad. Barcelona: Gedisa.

Braudel, F. (noviembre de 2006). La larga duración. RevistaAcadémica de Relaciones Internacionales, 1-36.

Burke, P. (2003). Formas de hacer historia (2. ed.). Madrid: Alianza Editorial.

Frampton, K. (1998). Historia crítica de la arquitectura moderna. Barcelona: Gustavo Gili.

Gausa, M., Guallart, V., Muller, W., Soriano, F., Porras, F., \& Morales, J. (2000). Diccionario Metápolis de arquitectura avanzada. Barcelona: Actar.

Giedion, S. (2009). Espacio, tiempo y arquitectura. Barcelona: Reverté.

Jelin, E. (2012). Los trabajos de la memoria (2. ${ }^{\mathrm{a}}$ ed.). Lima: Instituto de Estudios Peruanos.

Koolhaas, R. (2008). La ciudad genérica. Barcelona: Gustavo Gili.

López Soria, J.I. (2011). Ciudad e interculturalidad. Recuperado de Revista cultural electrónica: construyendo nuestra interculturalidad: http://intercultu- ralidad.org/attachments/article/103/ Lopez\%20Soria_Ciudad\%20e\%20interculturalidad.pdf

Lynch, K. (2010). La imagen de la ciudad (9. ed.). Barcelona: Gustavo Gili.

Monroy Nasr, R. (2007). Apreciación histórica y estética de la fotografia: un gran reto entre lo analógico y lo digital. Recuperado de www.scielo.br: http://www.scielo.br/ pdf/his/v26n2/a02v26n2.pdf

Norberg-Schulz, C. (2005). Principios de la arquitectura moderna. Barcelona: Reverté.

Reis-Alves, L.A. (4 de abril de 2009). El concepto de lugar. Recuperado de Arquitectura y territorio:http://furoramoris.blogspot.com/2009/04/elconcepto-de-lugar.html

Solà-Morales, I. de. (2002). Territorios. Barcelona: Gustavo Gili.

Sztulwark, P. (11 de enero de 2006). Ciudad Memoria: monumento, lugar y situación urbana. Recuperado de www.arqa.com: http://www.arqa.com/index.php/ esc/colaboraciones/ciudad-memoriamonumento-lugar-y-situacion-urbana.html

Vargas Ugarte, R. (1984). Historia general del Perú. Lima: Milla Batres.

Waisman, M. (1990). El interior de la historia. Historiografia arquitectónica para uso de latinoamericanos. Bogotá: Escala. 